\title{
TEACHING STATISTICAL METHODS IN ENGINEERING COURSES THROUGH WIND POWER DATA
}

\author{
José F.M. Pessanha $^{1}$, Fernando L.C. Oliveira ${ }^{2}$ and Reinaldo C. Souza ${ }^{2}$ \\ ${ }^{1}$ Rio de Janeiro State University - Uerj, Brazil \\ ${ }^{2}$ Pontifical Catholic University of Rio de Janeiro - PUC-Rio, Brazil \\ professorjfmp@hotmail.com
}

We describe examples based on real wind speed data designed to introduce engineering students at the post-calculus level to statistical methods and theory with real engineering problems. The examples cover some steps of the traditional wind power data analysis in order to develop in the student the data analysis capabilities and the statistical reasoning applied to the engineering problems.

\section{INTRODUCTION}

In general, the engineering students take only one semester course about Probability and Statistics, a short period to learn and develop the statistical reasoning applied to the engineering problems. In this context, it is rather important to motivate students with examples from real problems found in the engineering practice in order to show that statistics play an important role in the engineering.

This paper aims to describe a set of activities based on real wind speed data from public sources and designed to provide hands-on exercises in the classroom with R project ( $\mathrm{R}$ Core Team, 2014). Naturally the examples presented in this paper can be tailored to other computational languages. The examples are oriented to introduce students to statistical concepts and methods in special, data exploratory analysis, descriptive statistics and statistical inference. The main outcome that we expect to achieve with the adoption of these examples is to motivate and develop the data analysis capabilities and statistical reasoning of the students.

In addition, the proposed examples have important practical implications: it can develop and enhance the programming skills of the students, improve their abilities to solve problems as well as to point out links with other disciplines like electromechanical energy conversion, electric machines, power generation, power system control \& operation and power system economics. This initiative is an original idea that offers new ways to teach statistics to engineering students and show them the power of statistics at same time that present wind power, a valuable energetic resource.

\section{WIND POWER}

The statistics from World Wind Energy Association (WWEA, 2014) show that the total worldwide installed wind capacity reached $336 \mathrm{GW}$ by mid-2014, a growth of $13.5 \%$ over mid2013. Wind is a renewable natural resource and its utilization in the electricity production is one of the most promising alternatives to mitigate air pollution in the electric power generation.

However the wind is a non-controllable resource, it has a stochastic behavior and to cope with its variability the engineers apply statistical and probabilistic methods in the design of wind turbines and management of wind power plants.

The relationship between the wind speed $v(\mathrm{~m} / \mathrm{s})$ and the power generation $P$ (Watts) is defined by the power curve $P(v)$ illustrated in Figure 1 (Jangamshetti \& Rau, 1999). Examples of real power curves can be obtained in the catalogs of manufacturers of wind turbines available on the internet. The power generation begins at cut-in speed typically between 2 and $3 \mathrm{~m} / \mathrm{s}$. Thus, the power output rises rapidly up to achieve the rated output power at the rated wind speed between 12 and $17 \mathrm{~m} / \mathrm{s}$. At higher wind speeds the turbine holds the power generation near to the rated output, but when the turbine reach the cut-out wind speed around $25 \mathrm{~m} / \mathrm{s}$ the wind turbine power generation must be turned off in order to avoid risk of rotor damage. For assessment of wind power potential of a site we need know the power curve parameters of the wind turbine (cut-in, rated and cut-out speeds) and the parameters of the wind speed distribution (usually Weibull or Rayleigh) estimated from on-site wind speed measurements at hub-height. 


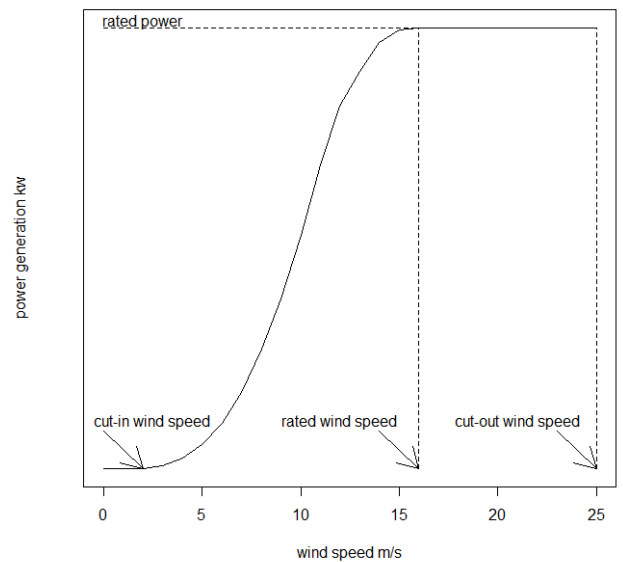

$P(v)=\left\{\begin{array}{c}0, v \leq V_{\text {in }} \\ 0.5 C_{p} \cdot \eta_{m} \cdot \eta_{g} \cdot \rho \cdot A \cdot v^{3}, V_{\text {in }}<v \leq V_{r} \\ 0.5 C_{p} \cdot \eta_{m} \cdot \eta_{g} \cdot \rho \cdot A \cdot V_{r}^{3}, V_{r}<v \leq V_{\text {out }} \\ 0, v>V_{\text {out }}\end{array}\right.$

where

$V_{\text {in }}=$ cut-in wind speed $(\mathrm{m} / \mathrm{s})$

$V_{r}=$ rated wind speed $(\mathrm{m} / \mathrm{s})$

$V_{\text {out }}=$ cut-out wind speed $(\mathrm{m} / \mathrm{s})$

$C_{p}=$ coefficient of performance (dimensionless)

$\eta_{m}=$ generator efficiency (dimensionless)

$\eta_{g}=$ gearbox efficiency (dimensionless)

$\rho=$ air density $\left(\mathrm{kg} / \mathrm{m}^{3}\right)$

$A=$ rotor swept area $\left(\mathrm{m}^{2}\right)$

Figure 1. Theoretical power curve

\section{EXAMPLES}

Below we present descriptions of four activities based on real wind speed data from public sources and designed to provide hands-on exercises in the classroom with $\mathrm{R}$ project.

\section{Activity 1: Download wind speed data from public sources}

There are several links on internet where we can find wind speed measurements available. For example, in Brazil the National Network of Environmental Data for Renewable Energy Resource Assessment (SONDA project) provides wind speed measurements from some Brazilian anemometric stations with ten minutes time resolution. The data are arranged on monthly electronic spreadsheets that can be downloaded free. This is a great opportunity to students learn how download data from internet through $\mathrm{R}$. The following code snippets downloads 12 monthly electronic spreadsheets with wind speed measurements from anemometric station located in São João do Cariri (7²2'54”S , 36³1’38”W), Brazil.

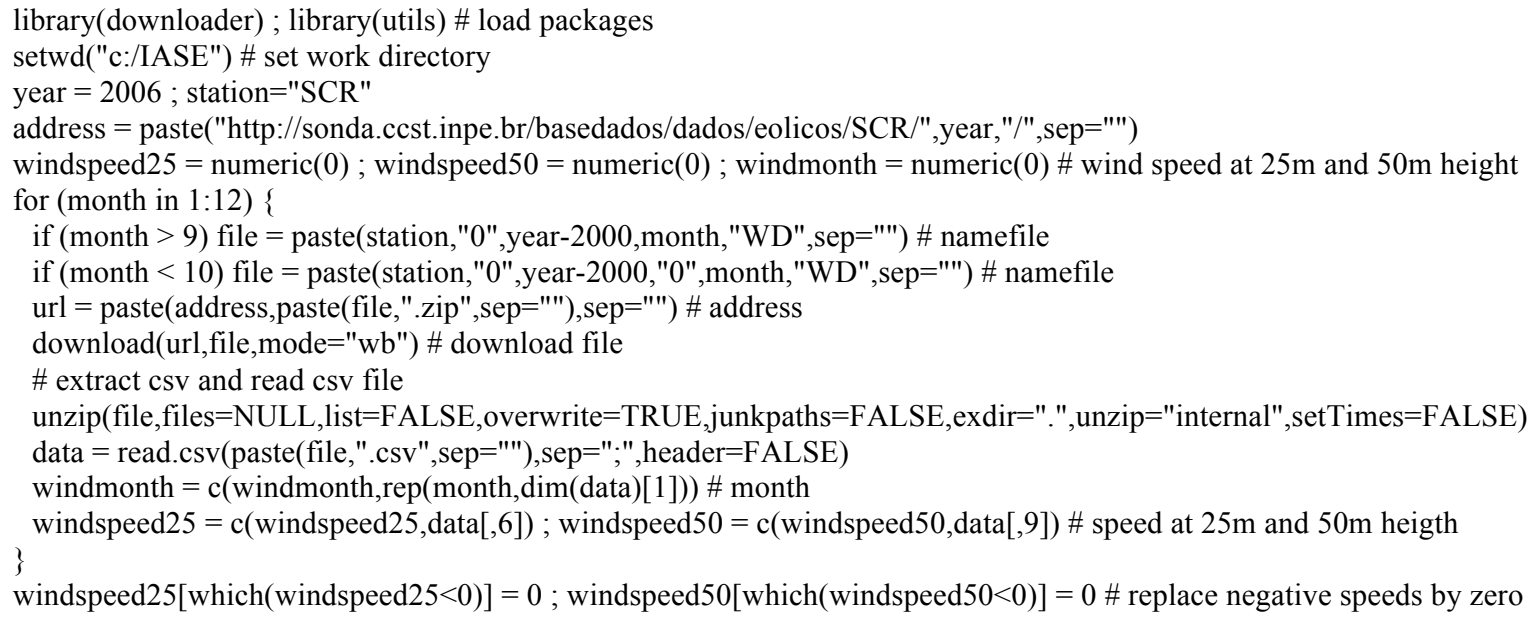

\section{Activity 2: Exploratory data analysis}

Based on the wind speed measurements the students can make an exploratory data analysis and compute some descriptive statistics from the wind speed dataset. For example, they can use the following $\mathrm{R}$ code to make the boxplots across the 12 months in Figure 2 and the descriptive statistics by month in Figure 3.

boxplot(windspeed50 windmonth,xlab="months",ylab="m/s",xaxt = "n",cex.axis=2,cex.lab=2) axis(1,at=1:12,labels=c("jan","feb","mar","apr","may","jun","jul","aug","sep","oct","nov","dec"),cex.axis=2) aggregate(windspeed50,by=list(windmonth), $\mathrm{FUN}=$ summary) 


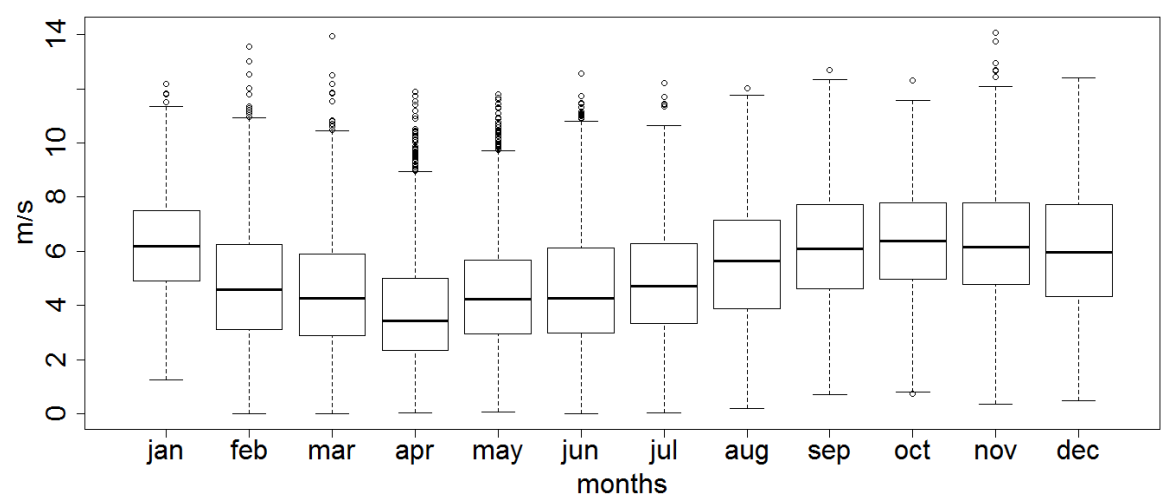

Figure 2. Boxplots of wind speed at $50 \mathrm{~m}$ height

$\begin{array}{lrrrrrrr} & \text { Group.1 } & \text { x.Min. } & \text { x.1st Qu. } & \text { x.Median } & \text { x.Mean } & \text { x. 3rd Qu. x.Max. } \\ 1 & 1 & 1.240 & 4.918 & 6.200 & 6.239 & 7.502 & 12.170 \\ 2 & 2 & 0.000 & 3.098 & 4.600 & 4.816 & 6.240 & 13.560 \\ 3 & 3 & 0.000 & 2.880 & 4.260 & 4.480 & 5.903 & 13.930 \\ 4 & 4 & 0.040 & 2.350 & 3.430 & 3.770 & 4.990 & 11.880 \\ 5 & 5 & 0.050 & 2.960 & 4.240 & 4.403 & 5.660 & 11.810 \\ 6 & 6 & 0.000 & 2.988 & 4.260 & 4.654 & 6.130 & 12.570 \\ 7 & 7 & 0.020 & 3.320 & 4.710 & 4.795 & 6.282 & 12.200 \\ 8 & 8 & 0.190 & 3.890 & 5.630 & 5.555 & 7.132 & 12.010 \\ 9 & 9 & 0.690 & 4.630 & 6.100 & 6.157 & 7.730 & 12.710 \\ 10 & 10 & 0.750 & 4.978 & 6.380 & 6.386 & 7.780 & 12.310 \\ 11 & 11 & 0.360 & 4.780 & 6.170 & 6.336 & 7.800 & 14.080 \\ 12 & 12 & 0.480 & 4.330 & 5.970 & 6.072 & 7.730 & 12.420\end{array}$

Figure 3. Descriptive statistics

Figures 2 and 3 show that the lowest median and mean wind speeds are observed in April and May. In addition, the average wind speed increases during the dry season (between May and November), but it follows a downward trend in the wet season (between December and April). This is an example of the energy complementarity between wind and hydro sources in Brazil (Palfi \& Zambon, 2013).

Figure 4 shows monthly histograms for the wind speed at $50 \mathrm{~m}$ height. The histograms were generated by the following $\mathrm{R}$ code. The distribution shape changes across the months and the statistics in Figure 5 indicate moderate skewed distribution in special at April and May when the kurtosis coefficient indicates moderate leptokurtic distribution.

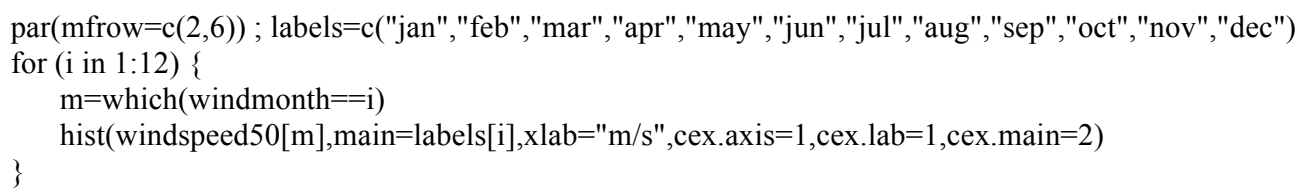

\section{Activity 3: Probability distribution fitting}

The Weibull probability distribution is the standard probabilistic model to describe the wind speed (Justus et al, 1978). The results from exploratory analysis indicate that the wind speed data are moderately skewed. Then, in this case the normal distribution is not the more appropriated model. The Weibull density function has two parameters as indicated in Figure 6: the shape parameter $(k)$ and the scale parameter $(c)$. The scale parameter $(c)$ is proportional to the wind speed average (3) while the shape parameter $(k)$ is related to the constancy of the wind, a higher $k$ value imply in a lower wind speed variance (4). Additionally, the scale parameter $(c)$ is expressed in $\mathrm{m} / \mathrm{s}$ and the shape parameter $(k)$ is dimensionless. In general $k$ is a number between 2 and 3 , but in the areas where prevailing trade winds like in the Brazilian Northeast the shape parameter can be greater than 6 (Amarante et al, 2001). 


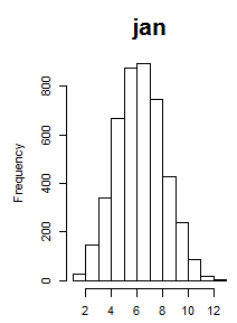

$\mathrm{m} / \mathrm{s}$

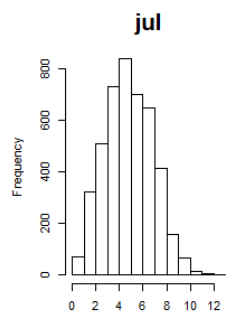

$\begin{array}{llll}4 & 6 & 8 \\ & \mathrm{~m} / \mathrm{s}\end{array}$

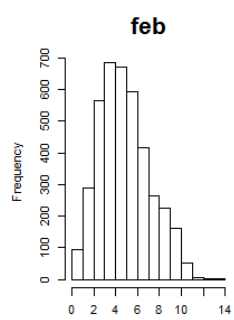

$\mathrm{m} / \mathrm{s}$

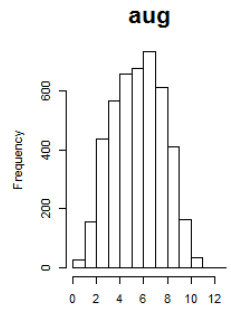

$\mathrm{m} / \mathrm{s}$

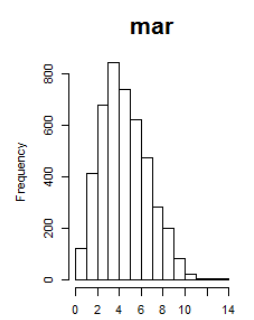

$\mathrm{m} / \mathrm{s}$

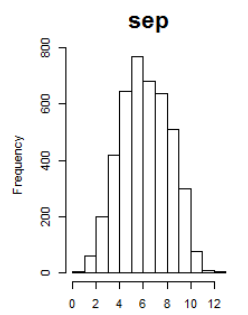

$\mathrm{m} / \mathrm{s}$

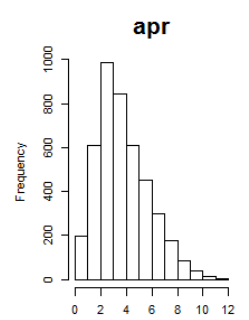

$\mathrm{m} / \mathrm{s}$

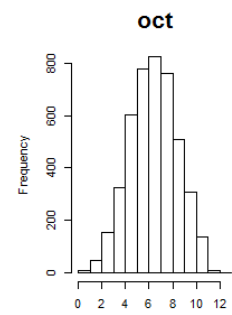

$\mathrm{m} / \mathrm{s}$

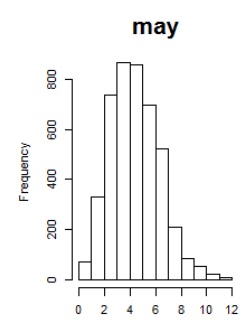

m/s

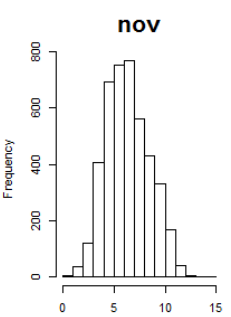

$\mathrm{m} / \mathrm{s}$

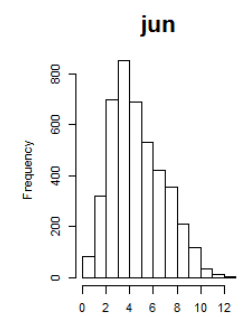

$\mathrm{m} / \mathrm{s}$

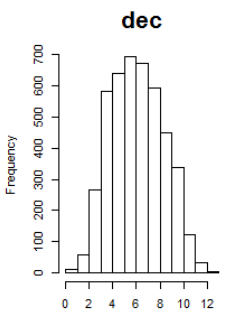

$\mathrm{m} / \mathrm{s}$

Figure 4. Monthly histograms

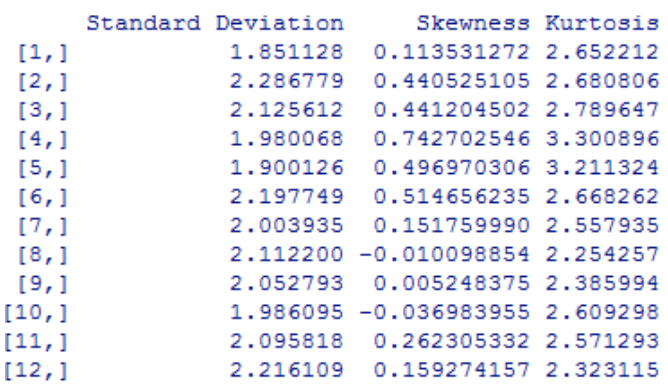

library(moments) \# load package moments others_stats $=$ matrix $(0,12,3)$

colnames(others_stats) $=\mathrm{c}($ "Standard

Deviation","Skewness","Kurtosis")

for (i in 1:12) \{

$\mathrm{m}=$ which $($ windmonth $==\mathrm{i}$ )

$\mathrm{ws}=$ windspeed $50[\mathrm{~m}]$

others_stats[i,]=c(sd(ws),skewness(ws),kurtosis(ws)) \}

print(others_stats)

Figure 5. Monthly standard deviation, skewness and kurtosis

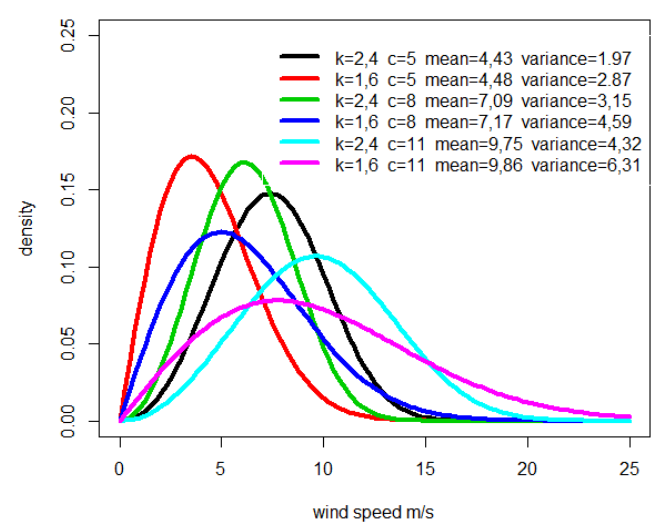

$$
\begin{aligned}
& v \sim \operatorname{Weibull}(k, c) \\
& f(v)=\frac{k}{c}\left(\frac{v}{c}\right)^{k-1} \exp \left[\left(-\frac{v}{c}\right)^{k}\right] v>0 \\
& E(v)=c \Gamma\left(1+\frac{1}{k}\right) \\
& \sigma^{2}(v)=c^{2}\left[\Gamma\left(1+\frac{2}{k}\right)-\Gamma\left(1+\frac{1}{k}\right)^{2}\right]
\end{aligned}
$$

Figure 6. Weibull probability distribution model

The parameters $c$ and $k$ can be estimated by maximum likelihood (function parweibull from MASS package) or by the method of moments. In this paper we show the approach proposed by Blischke \& Scheur (1986) to the method of moments where the parameters are determined in order to satisfies the following equations where $\bar{X}$ and $\mathrm{S}^{2}$ are the wind speed sample statistics:

$$
\bar{X}=c \Gamma\left(1+\frac{1}{k}\right)
$$

$$
S^{2}=c^{2}\left[\Gamma\left(1+\frac{2}{k}\right)-\Gamma\left(1+\frac{1}{k}\right)^{2}\right]
$$


The shape parameter estimate $\hat{k}$ is the root of the transcendental equation (7) and the scale parameter estimate $\hat{c}$ is obtained from equation (3) replacing $k$ by $\hat{k}$ as shown in equation (8). Figure 7 shows the monthly estimates for $k$ and $c$ obtained by the R code below.

$$
\begin{aligned}
& \frac{S^{2}}{X^{2}}=\left(\Gamma\left(1+\frac{2}{\hat{k}}\right) / \Gamma\left(1+\frac{1}{\hat{k}}\right)^{2}\right)-1 \\
& {[1,] \quad 3.759620 \quad 6.907386} \\
& {[2,] 2.225616 \quad 5.437190} \\
& {[3,] 2.227603 \quad 5.058011} \\
& \text { [4,] } 1.989638 \quad 4.253927 \\
& \text { [5,] } 2.476684 \quad 4.964025 \\
& \text { [6, ] } 2.239725 \quad 5.254999 \\
& {[7,] 2.566573 \quad 5.400051} \\
& {[8,] 2.852436 \quad 6.233648} \\
& {[9,] 3.302877 \quad 6.863898} \\
& {[10,] 3.5683197 .090480} \\
& {[11,] 3.332187 \quad 7.060459} \\
& {[12,] 2.9857736 .800583}
\end{aligned}
$$

$$
\hat{c}=\bar{X} / \Gamma\left(1+\frac{1}{\hat{k}}\right)
$$

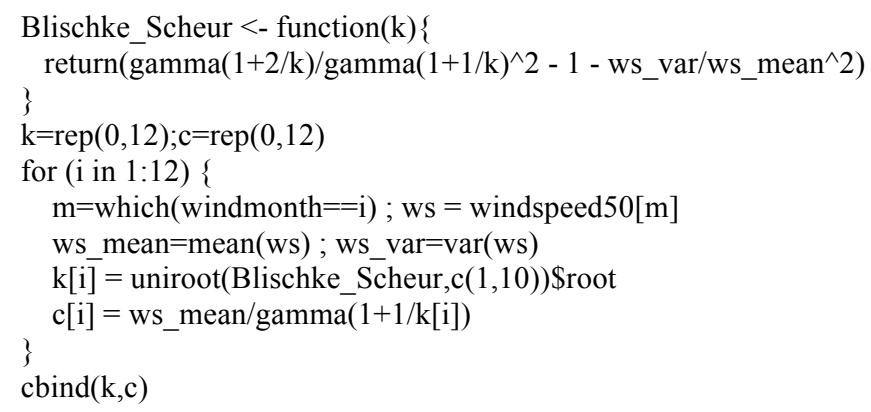

Figure 7. Monthly estimates for the shape and scale parameters of the wind speed at $50 \mathrm{~m}$ height

\section{Activity 4: Estimating the capacity factor}

There are many manufacturers and types of wind turbines and an engineer should choice the turbine model more appropriated to the wind behavior in a wind power plant project. A key parameter in the choice of turbine model is the capacity factor $(C F)$ defined by the ratio between the average power output $E(P(v))$ and the rated power output $P_{\max }$. Jangamshetti \& Rau (1999) presents the following formula to estimate the capacity factor of a wind turbine:

$$
C F=\frac{E(P(v))}{P_{\max }}=\frac{1}{v_{r}^{3}} \int_{V_{\text {in }}}^{V_{r}} v^{3} f(v) d v+\int_{V_{r}}^{V_{\text {out }}} f(v) d v
$$

where $f(v)$ is the probability density function of the wind speed at hub height and $V_{i n}, V_{r}$ and $V_{\text {out }}$ are respectively the cut-in, rated and cut-out speeds in the power curve (Figure 1).

In the modern wind power plants the hub height of the turbines can achieve more than 100 $\mathrm{m}$ height, but the wind speed measurements from SONDA are taken at $25 \mathrm{~m}$ and $50 \mathrm{~m}$ heights. Then, it is necessary to extrapolate the estimates for the Weibull parameters to the hub height. This is an example of function of a random variable. The relationship between the wind speed and height can be modeled by the power law (Jangamshetti \& Rau, 1999) in which the wind speed ratio at two different heights $(h$ and $50 \mathrm{~m}$ ) is a power function of the ratio between the respective heights:

$$
\frac{V_{h}}{V_{50 m}}=\left(\frac{h}{50}\right)^{\alpha}
$$

$$
\hat{\alpha}=\frac{\log \left(\overline{V_{50 m}}\right)-\log \left(\overline{V_{25 m}}\right)}{\log (50)-\log (25)}
$$

where the power law index $\alpha$ can be determined by the equation (11) based on mean wind speed at $25 \mathrm{~m}$ and $50 \mathrm{~m}$ height.

Based on power law we can extrapolate the wind speed measurements to a hub height $h$ and then apply the method of moments to estimate the parameters $k$ and $c$ at new height $h$. Instead, we can apply the following corrections presented by Justus et al (1978).

$c_{h}=c_{50 m}\left(\frac{h}{50}\right)^{\frac{0.37-0.088 \log \left(c_{50 m}\right)}{1-0.088 \log (50 / 10)}}$

$$
k_{h}=k_{50 m} \frac{1-0.088 \log (50 / 10)}{1-0.088 \log (h / 10)}
$$


Consider a wind turbine with rated power equal to $1.8 \mathrm{MW}$, hub height $119 \mathrm{~m}$ and which cut-in speed, rated speed and cut-out speed are $3 \mathrm{~m} / \mathrm{s}, 12 \mathrm{~m} / \mathrm{s}$ and $25 \mathrm{~m} / \mathrm{s}$ respectively. In order to calculate the capacity factor we should correct the parameters of the wind speed probability density function at $50 \mathrm{~m}$ height to $119 \mathrm{~m}$ height. The following $\mathrm{R}$ code applies the equations (12) and (13) to correct the parameters $k$ and $c$ and then compute the monthly capacity factor.

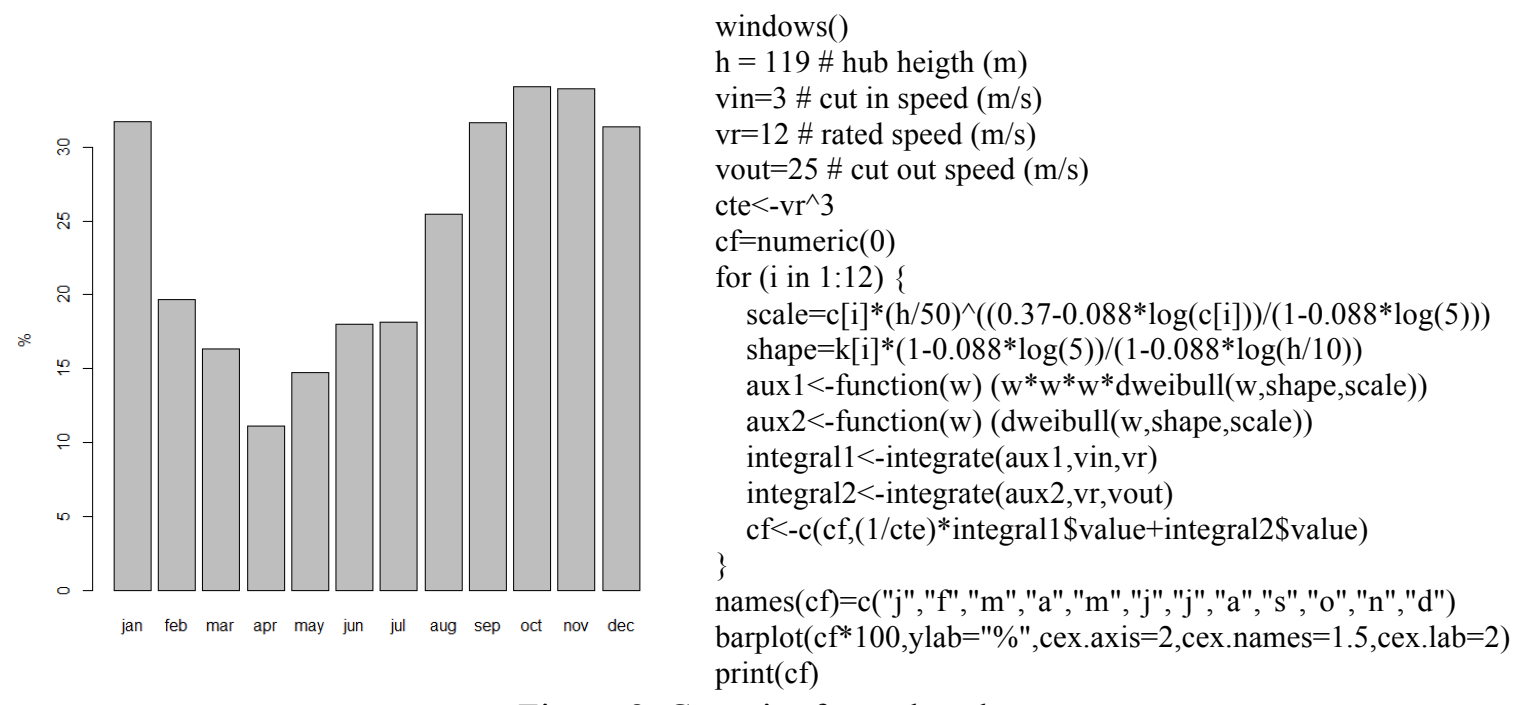

Figure 8. Capacity factor barplot

Figure 8 shows that the monthly capacity factors oscillate in the $10-35 \%$ range and that relatively high values (above 30\%) occur between September and January. Based on these results we can estimate the amount of energy $(\mathrm{kWh})$ produced in a month by:

Energy $($ month $i \mathrm{MWh})=$ Total operating hours in month $i \mathrm{x}$ Rated power $\mathrm{MW} \times \mathrm{x} C F($ month $i)$

\section{CONCLUSION}

In the wind power we can find good examples to teach statistical methods and theory based on real engineering problems to engineering undergraduate students. In this paper we show some examples to a first course on statistics, the examples presented cover the steps of the traditional wind speed data analysis since the data acquisition on internet, statistical analysis up to the procedures to estimate the capacity factor and the amount of monthly energy production. In addition, there are many other topics for advanced courses on Statistics, for example, data cleaning, circular statistics, non-parametric methods, stochastic simulation and time series analysis \& forecast.

\section{REFERENCES}

Amarante, O. A. C., Brower, M., Zack, J., \& Sá, A. L. (2001). Brazilian Wind Energy Potential Atlas, Centro de Pesquisas de Energia Elétrica: Brasília.

Blischke, W. R., \& Scheuer, E. M. (1986). Tabular aids for fitting Weibull moment estimates, Naval Research Logistics Quaterly, 33, 145-153.

Jangamshetti, S. H. J., \& Rau, V. G. (1999). Site matching of wind turbine generators: a case study, IEEE Transactions on Energy Conversion, 4(4), 1537-1543.

Justus, C. G., Hargraves, W. R, Mikhail, A., \& Graber, D. (1978). Methods for estimating wind speed frequency distributions. Journal Applied Meteorology 17, 350-353.

Palfi, G., \& Zambon, R. (2013). Hydro and Wind Power Complementarity and Scenarization in Brazil. World Environmental and Water Resources Congress, Cincinnati.

R Core Team (2014). R: A language and environment for statistical computing. R Foundation for Statistical Computing, Vienna, Austria. URL http://www.R-project.org/.

WWEA - World Wind Energy Association (2014). Half-year Report 2014, September. 